\title{
Research on the Humanistic Character of Outdoor Public Seats on Campus
}

\author{
$\operatorname{Li~Liu}^{1, *}$ \\ ${ }^{1}$ Department of Environmental Design, Central South University, Changsha, Hunan, China \\ *2274286261@qq.com
}

\begin{abstract}
As the construction of Chinese universities continues, campuses keep expanding. Outdoor public seats play an important role in campus public space, its current status and future directions have not been concerned. This study focuses on the humanistic character of outdoor public seats on campus, the current situation of outdoor public seats be analysed in four typical universities, problems in outdoor public seats design on campus was discovered, and the solution was proposed. The main contents include: (1) Using the contrast method for the analysis of the current situation of outdoor public seats on campuses. A horizontal comparison from a geographical perspective (southern China and northern China) and a vertical comparison from a historical perspective (The history of four universities is 21, 67, 70 and 1045 years). (2) Summarising the humanistic factors affecting the character of outdoor public seats on campuses, analyse the precise reasons that underlie it. (3) Providing design suggestions for improving the humanistic character of outdoor public seats on campuses. The results of the study were as follows: (1) The outdoor public seats on campuses have four features that are phasic construction, regional distribution, cultural explicitness, and pioneering design. (2) The most important humanistic factors affecting the characters of outdoor public seats on campus are the history, philosophy, and layout of the university. (3) In view of the lack of humanity of outdoor public seats on campuses, three design methods of systematization, humanization and enculturation are proposed. The study of the current situation and design direction can drive the further development of outdoor public seats on campuses to enhance the humanistic spirit of campuses.
\end{abstract}

Keywords: Humanistic character, Outdoor public seats, Campus, Culture.

\section{INTRODUCTION}

With the construction of Chinese universities enters a new stage, it is necessary to create a campus environment with a humanistic atmosphere for teachers and students. The campus environment plays an important role in the formation of humanistic values of student [1]. As an important tool for interpreting campus culture in the environment, the humanistic character improvement of outdoor public seats is the key pathway to shape student's values. However, the humanistic connotation of outdoor public seats has been usually neglected in studies.

Humanistic connotation emerges and develops in dynamic interaction between the individual and their spatial environment. Human seat interaction is highly complex due to the interaction between human, seats and activities [2]. Outdoor public seats are medium between the physical, humanistic environment and users in university. Therefore, it is the critical research points how to improve the humanistic character of outdoor public seats in people-environment interactions during daily activities through exploring the current status of outdoor public seats on campus.

\section{LITERATURE REGARDING OUTDOOR PUBLIC SEATS}

This study summarises the definition and classification of public seats, also reviews domestic and foreign research on public seats. Focusing on exploring the relevance of outdoor public seats and campus culture, the study analysing cases of campus outdoor public seats to establish a basis for the next step of research.

\subsection{Definition and classification}

As a public facility, public seats are an important element that expresses the content of outdoor public space, and it is also the material basis of space functions. As an important part of the public facility system, the design of public seats reflects the economic level and the 
quality of life, also reveals the unique cultural imagery and historical connotation. Public seats are classified according to different classification standards such as the number of users, use environment, ways of use, material, combination, and shape, etc. In addition, outdoor public seats can be divided into movable and fixed types.

Table 1. Classification of public seats

\begin{tabular}{cc}
\hline Standards & Specific category \\
\hline Number of users & Single, double, group, etc. \\
Use environment & Indoor, outdoor, etc. \\
Ways of use & Sitting, leaning, lying, etc. \\
Material & Wood, metal, paper, plastic, etc. \\
Combination & Enclosed, semi-enclosed, etc. \\
Shape & Linear, streamlined, etc. \\
\hline
\end{tabular}

\subsection{Research status and trends}

The concept of public facilities originated in the United Kingdom and was called "street furniture" at the time. European and American countries pay great attention to outdoor public seats in campuses, squares, and streets [3], so that various outdoor public seats are integrated with the surrounding environment [4]. The design of public facilities in China started late, and the concept of urban public furniture began in 1998. There are many problems in the design of public facilities in China, such as lack of innovation, ignoring ergonomics, and failing to reflect local culture.

Table 2. Comparison of design points

\begin{tabular}{cc}
\hline Chinese & Foreign \\
\hline Harmony with the environment & Art form \\
Link people and cities & Ekistics \\
"City can sit" & Ergonomics \\
Interactive design concept & Humanity design \\
\hline
\end{tabular}

\subsection{Outdoor public seats and campus cultural landscape}

The humanistic characteristics of the campus landscape refers to create a humanistic atmosphere through public facilities that reflect culture, and changes with the campus environment. Each campus has its own characteristics, which is influenced by nature, history, and culture. Outdoor public seats on campus not only provides physiological satisfaction for users, but also fulfils their social, cultural, psychological and ideological needs [5]. Considering the campus humanistic spirit when design outdoor public seats to prevent damage to the integrity of the campus cultural landscape.

\subsection{Excellent design cases analysis}

Public seats are a space element that cannot be ignored in students' daily life, and they are also the main place for teachers and students to communicate. Therefore, the design of outdoor public seats on campus is crucial to the improvement of the humanistic character. This study compares excellent design cases and analyses their design methods, as shown in Table 3.

In sum, after studying literature and data, it is found that there is a certain gap in the design of outdoor public seats between China and other countries, through comparing the development process and variation trends of outdoor public seats. The design of many outdoor public seats on campus does not reflect the humanistic character, and even blindly copied the works of some well-known designers.

\section{METHODS}

In a special environment like universities, the design of outdoor public seats should pay more attention to dissemination, rendering and enlightenment functions of cultural. However, universities ignore the design of outdoor public seats in terms of humanistic character of actual construction. How does it highlight campus culture requires more comprehensive methods. The research methods applied in this paper are as follows:

(1) Comprehensive Research Method: summarizing information from multiple perspectives to strengthen the systematic understanding of public seats, and enhance the rationality and innovation of this research.

(2) Field Research Method: investigated, recorded, analysed and summarized the current situation of outdoor public seats in Central South University (CSU) and Hunan University (HNU) in Changsha, Capital Normal University (CNUEF) and Minzu University of China (MUC) in Beijing.

(3) Comparative Research Method: comparing the outdoor public seats on campus in Changsha and Beijing from the geographical and historical perspectives through first-hand data, problems and deficiencies were discovered to improve the expression of the humanistic spirit of outdoor public seats on campus.

\section{RESULT}

\subsection{Features of campus outdoor public seats}

It is found that there are many shortcomings in the design of outdoor public seats on campuses. The investigated outdoor public seats lack aesthetics, creativity and humanistic character, indicating that the trend of public art design has not yet involved public facilities such as outdoor public seats. The features of campus outdoor public seats are as follows and show in Table 4. 


\subsubsection{Phasic construction}

In the process of expansion of the university, different construction period lefts a unique impact to outdoor public seats on campus. Public spaces are the main manifestation of university expanding, which exchanging experiences and fostering society relationships through public facilities [6]. The outdoor public seats of CSU have the obvious feature of phasic construction. CSU was formed by the merger of three universities in April 2000. The difference in economic development and education investment has led to the staged stratification of the construction of outdoor public seats during 21 years. Therefore, mastering the rules of university planning can understand the construction direction of outdoor public seats on campus better.

Table 3. Comparison of design cases

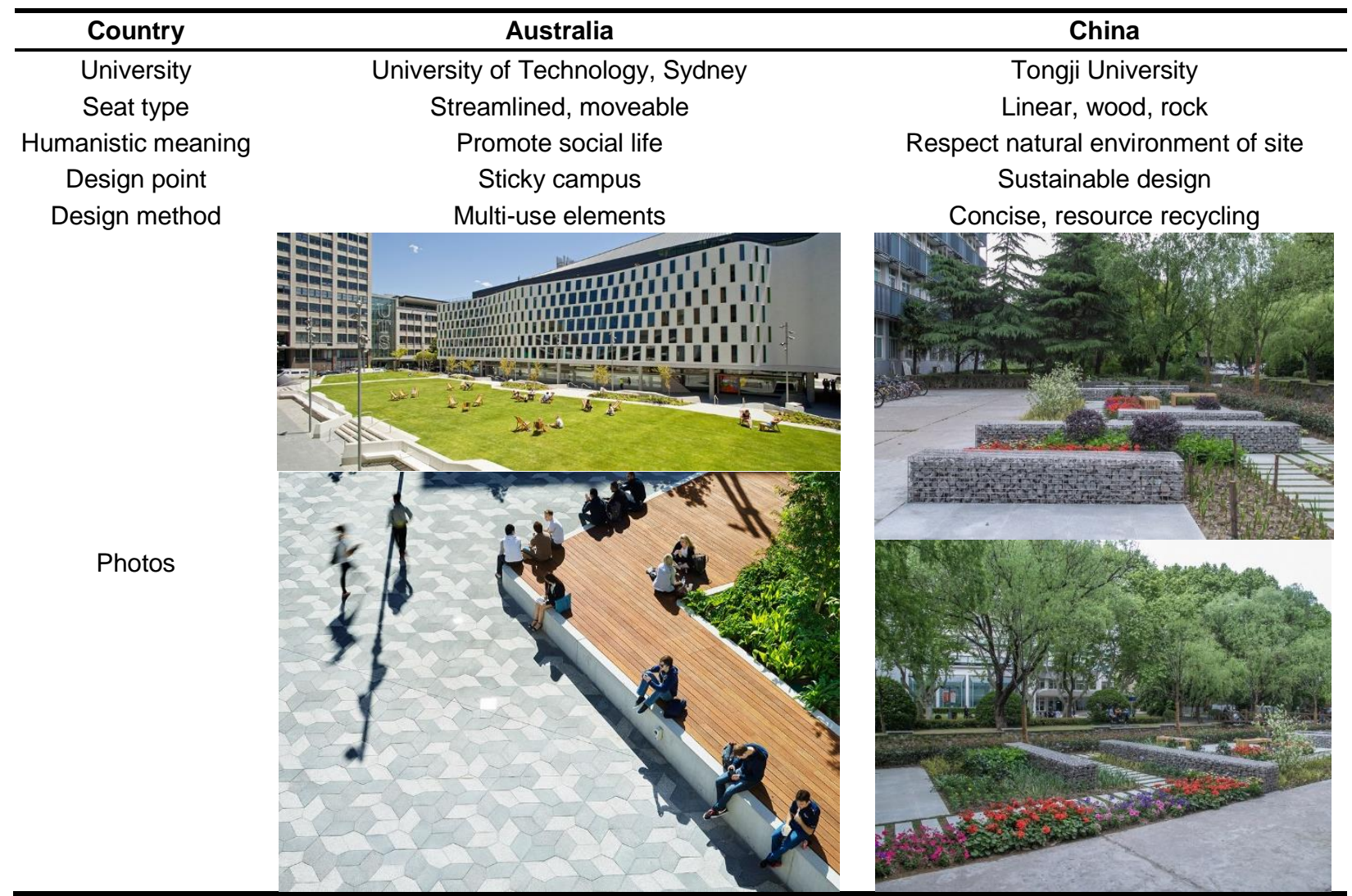

\subsubsection{Regional distribution}

According to the relationship between human behaviour and the environment, comfortable public facilities will increase the frequency of people's activities in this place. Due to the differences in geographic location and cultural environment, the distribution areas of outdoor public seats in different schools have their own characteristics.

The campus outdoor public seats of CSU are mainly distributed in the waterfront space around the Yudai River, and are characterized by being arranged around the open waterfront space. The boundary of HNU is not obvious because of the campus is integrated with the street and residences. Therefore, outdoor public seats on campus of HNU are distributed along the streets, and Yuelu Mountain is its key distribution area. The outdoor public seats of CNUEF are distributed in sports and entertainment spaces such as basketball courts. The public space of MUC is oriented on the central axis, and campus outdoor public seats are arranged around the axis.

\subsubsection{Cultural explicitness}

The unique campus culture is an important part of social culture, and it is the sum of spiritual culture and material culture formed in a specific campus environment. For university campuses, places are social spaces and nodes of knowledge generation and distribution [7]. When the spirit is conveyed by outdoor public seats on campus, it needs to rely on external and explicit factors such as Chinese character.

HNU uses public seats to express culture with the help of stone carvings. It can be seen that the design of outdoor public seats on campus can create a good campus image, enhance the connotation of campus culture, spread the spirit of campus culture, and increase the visibility of the campus. 


\subsubsection{Pioneering design}

University are vital actors in the global knowledge economy, central players in emergent innovation systems and active agents that can play a driving role in the innovation process of outdoor public seats on campus [8]. Advanced design trends and artistic concepts have influenced the design of outdoor public seats in Chinese universities. The pioneering design of outdoor public seats on campus is usually done by professional designers and design teachers. The design of outdoor public seats on the campus of HNU are obviously avant-garde. The emergence of avant-garde design is closely integrated with the stage of construction and combines the cultural heritage of thousands of years. Therefore, when introducing advanced design concepts, we should focus on local culture and symbols to build campus cultural landscape features.

Table 4. Features of outdoor public seats on four campuses

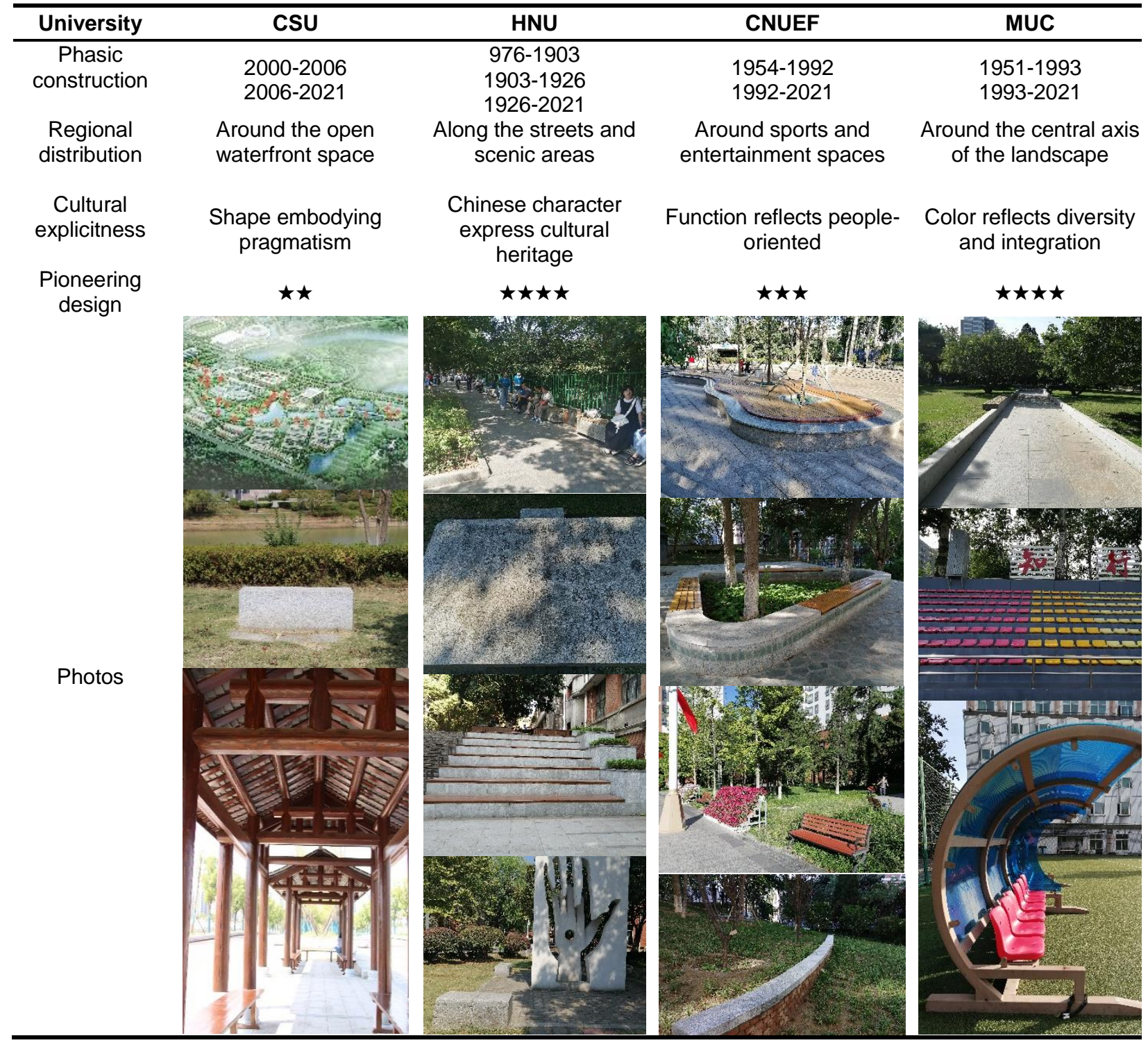

\subsection{The effect factors of the humanistic character of campus outdoor public seats}

It is found that there are three humanistic factors affecting the characters of campus outdoor public seats through the analysis of the outdoor public seats of four universities.

\subsubsection{School history}

As the cultural center of a region, the university campus is formed by a long history and uninterrupted cultural heritage. Campus culture plays a very important role in the campus environment. A healthy and elegant campus culture atmosphere have guiding, regulating, stimulating, and cohesive functions. 
Hunan University, which has a history of 1045 years, has always maintained the continuity of campus cultural through the changes of Song, Yuan, Ming and Qing dynasties. The spirit of "seeking truth from facts, dare to be the first" has been formed, which has promoted innovation in the design of outdoor public seats on campus.

Table 5. The philosophy of universities

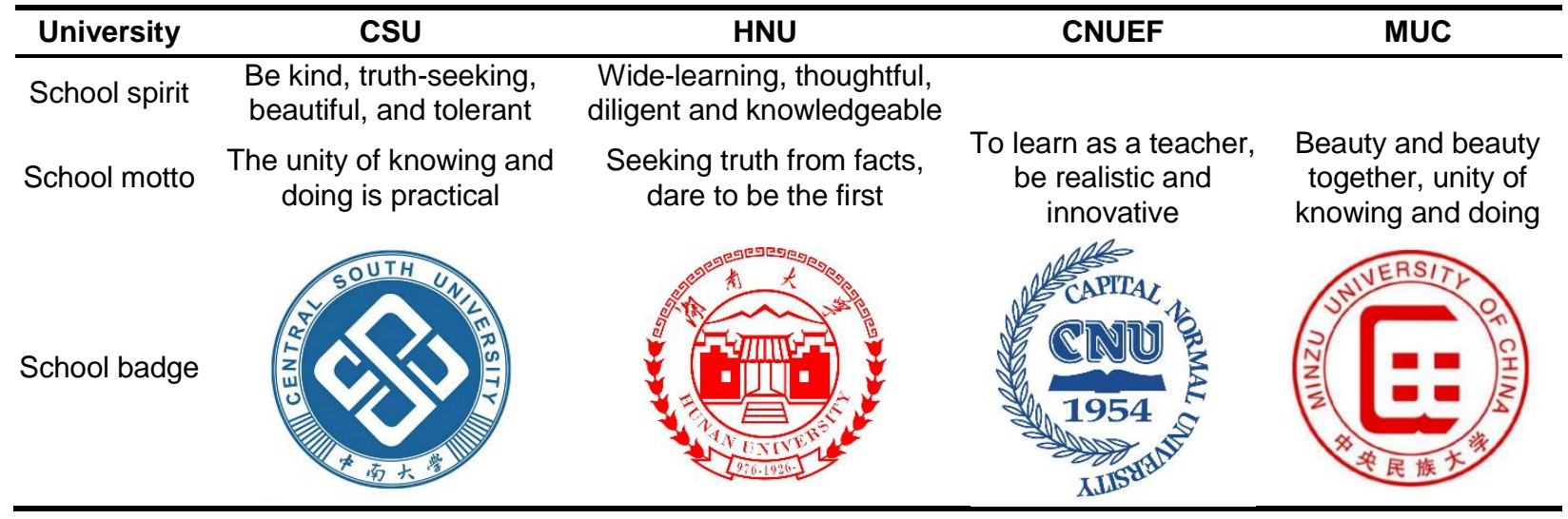

\subsubsection{School philosophy}

The philosophy is the cultural core of a university and reflects their cultural position. The badges and motto of school are the symbols that designer should consider, which convey the inner spirit and development direction of a university. These cultural symbols that have a major impact are important considerations in the design of outdoor public seats on campus.

The school culture of CSU is practical, and its outdoor public seats on campus are made of anticorrosion wood and stone, which embodies the practical spirit. The school culture of the MUC emphasizes equality and reflects the seriousness of the multi-ethnic unified system. This is the reason why the outdoor public seats on campus are distributed along the central axis, as shown in Table 5.

\subsubsection{School layout}

The campus is affected by factors such as historical and cultural relics, celebrities and local social characters during construction. These factors have played a positive role in the layout of the campus. Different characteristics of the built environment affect an individual's physical abilities, emotions, intentions and meaningful relations [9]. The original natural lakes and artificial fish ponds of CSU are retained as landscape water systems. As CSU is located along the Xiangjiang River and has natural hydrophilicity, it has formed the layout of campus public seats along the water landscape system.

\subsection{Design methods to enhance the humanistic character of campus outdoor public seats}

In the new stage of development, universities are more focused on how to create a humanistic environment so that the campus can meet the growing cultural needs of teachers and students. For this kind of demand, how to meet the high-level psychological pursuit of teachers and students on campus is very important for the design of outdoor public seats on campus. The three design principles of systematization, humanization and enculturation promote users to experience the deep cultural artistic conception of the site and enhance the humanistic characteristics of outdoor public seats on campus.

\subsubsection{Systematization}

A university campus is an organic combination of nature and society. As a part of campus public facilities, outdoor public seats are related to people, physical space, cultural atmosphere, and social environment. These parts are interconnected and interacted to form a whole, which contains not only material pursuits, but also cultural expressions. Therefore, the design of outdoor seats should be coordinated with the overall planning of the campus, and systematic design should be carried out. The effectiveness and feasibility of the design from the natural environment, geology and hydrology, vegetation conditions, climate conditions, campus culture and other aspects of the site should be analysed. Integrating campus outdoor public seats with the surrounding natural landscape, built environment, social environment and regional characteristics, in order to express the humanistic character of campus outdoor public seats in a coherent system.

\subsubsection{Humanization}

Public spaces at university campuses are important knowledge hubs [6]. Outdoor public seats are physical manifestation of the spiritual dimension, which not only improves the visual effect of the campus landscape, but also reflects campus culture and moral education. 
Outdoor public seats play a role in shaping the personality of young students, reflecting not only the superficial humanistic spirit of the campus, such as the academic atmosphere and cultural environment, but also the deeper humanistic spirit, such as the values, morals and aesthetics of teachers and students. Therefore, the most important design principle for outdoor public seats on campus is humanization.

With a cultural identity, outdoor public seats on campus can represent the cultural connotation of the campus and form a distinctive campus culture. Excellent design of campus outdoor public seats should materialise the cultural connotations of the campus through artistic methods, leading the teachers and students to experience and convey the spirit of the campus in a subtle way.

\subsubsection{Enculturation}

As an important place for providing education and disseminating culture, universities undertake the major mission of the development of human civilization. Universities reflect the level of higher education in China. Outdoor public seats on campus are responsible for education and play a role in aesthetic edification and cultural dissemination. Therefore, it is necessary to design outdoor public seats on campus with the purpose of education. Teachers and students experience the cultural conveyed by the physical art in daily life and form a good cultural accumulation for the campus.

\section{CONCLUSION}

This study found that the campus outdoor public seats lacked humanistic character, after the theoretical research and field investigation of the campus outdoor public seats. Designing outdoor public seats with cultural elements, systematically considering the people-seat-environment interactions, and using edifying expressions, can effectively improve the humanistic character of outdoor public seats on campuses. Nevertheless, how to make teachers and students better sense the humanistic connotation of campus outdoor public seats still needs further research, and the ways of perceiving remain to be explored.

This research explores the internal factors behind the appearances of lacked humanistic character, and proposes design methods that enhance the humanistic character of outdoor public seats on campus, which can bring new ideas to the future development of campus outdoor public seats. Although the campus outdoor public seat is a small element, it is of great significance to the campus environment and humanistic values formation. It is worthwhile for designers to think carefully about how to integrate various outdoor public seats with the surrounding environment to form a diverse humanistic environment.

\section{ACKNOWLEDGMENTS}

This research received funding from the Independent exploration and innovation project of CSU 'Research and Application of Temporal and Spatial Changes of Mine Landscape Patterns and the Driving Factors: A Case Study of Lengshuijiang Mine in Hunan' (2020zzts349).

\section{REFERENCES}

[1] S. Fedorenko, I. Shkilna, K. Zhurba, O. Reipolska, O. Tretiak, O. Lytovchenko. The Family and the School: Interaction in Shaping of Pupils' Humanistic Values. Laplage Em Revista. 2021, 7 (3): 55-63

[2] X. Wang, M. Cardoso, G. Beurier. Effects of Seat Parameters and Sitters' Anthropometric Dimensions on Seat Profile and Optimal Compressed Seat Pan Surface. Applied Ergonomics. 2018, 73: 13-21

[3] K.W.M. Siu, K.S.L. Wong. Flexible Design Principles. Facilities. 2015, 33 (9/10): 588-621

[4] H.-S. Chang, C.-H. Liao. Exploring an Integrated Method for Measuring the Relative Spatial Equity in Public Facilities in the Context of Urban Parks. Cities. 2011, 28 (5): 361-371

[5] E. Allameh, M. Heidari. Sustainable Street Furniture. Periodica Polytechnica. Architecture. 2020, 51 (1): 65-74

[6] I. Soares, G. Weitkamp, C. Yamu. Public Spaces as Knowledgescapes: Understanding the Relationship between the Built Environment and Creative Encounters at Dutch University Campuses and Science Parks. 2020, 17 (20): 7421

[7] P. Meusburger. Knowledge Environments in Universities. Hungarian Geographical Bulletin. 2015, 64 (4): 265-279

[8] E. Deiaco, A. Hughes, M. McKelvey. Universities as Strategic Actors in the Knowledge Economy. Cambridge journal of economics. 2012, 36 (3): 525541

[9] R. Withagen, H.J. de Poel, D. Araújo, G.-J. Pepping. Affordances Can Invite Behavior: Reconsidering the Relationship between Affordances and Agency. New ideas in psychology. 2012, 30 (2): 250-258 